Article

\title{
Surface-Enhanced IR-Absorption Microscopy of Staphylococcus aureus Bacteria on Bactericidal Nanostructured Si Surfaces
}

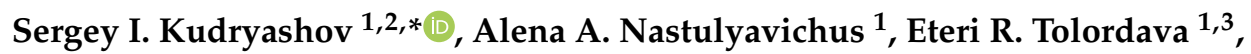 \\ Alexey N. Kirichenko ${ }^{4}$, Irina N. Saraeva ${ }^{1}$, Andrey A. Rudenko ${ }^{1}$, Yulia M. Romanova ${ }^{3}$, \\ Andrey Yu. Panarin ${ }^{5}$, Andrey A. Ionin ${ }^{1} \mathbb{D}$ and Tatiana E. Itina ${ }^{6} \mathbb{D}$ \\ 1 Lebedev Physical Institute, 119991 Moscow, Russia; ganuary_moon@mail.ru (A.A.N.); \\ tolordava.eteri@yandex.ru (E.R.T.); heddwch@mail.ru (I.N.S.); aa_rudenko@mail.ru (A.A.R.); \\ ioninaa@lebedev.ru (A.A.I.) \\ 2 ITMO University, 197101 St. Petersburg, Russia \\ 3 N.F. Gamaleya Federal Research Centre of Epidemiology and Microbiology, 123098 Moscow, Russia; \\ genes2007@yandex.ru \\ $4 \quad$ FSBI TISNCM, 108840 Moscow, Russia; akir73@mail.ru \\ 5 B.I. Stepanov Institute of Physics NAS Belarus, 220072 Minsk, Belarus; a.panarin@ifanbel.bas-net.by \\ 6 Laboratoire Hubert Curien, UMR CNRS 5516/UJM/Univ. Lyon, 42000 Saint-Etienne, France; \\ tatiana.itina@univ-st-etienne.fr \\ * Correspondence: kudryashovsi@lebedev.ru; Tel.: +7-499-1326083
}

Academic Editor: Ashok Kakkar

Received: 15 November 2019; Accepted: 5 December 2019; Published: 7 December 2019

\begin{abstract}
Surface-enhanced IR absorption (SEIRA) microscopy was used to reveal main chemical and physical interactions between Staphylococcus aureus bacteria and different laser-nanostructured bactericidal Si surfaces via simultaneous chemical enhancement of the corresponding IR-absorption in the intact functional chemical groups. A cleaner, less passivated surface of Si nanoripples, laser-patterned in water, exhibits much stronger enhancement of SEIRA signals compared to the bare $\mathrm{Si}$ wafer, the surface coating of oxidized Si nanoparticles and oxidized/carbonized $\mathrm{Si}$ (nano) ripples, laser-patterned in air and water. Additional very strong bands emerge in the SEIRA spectra on the clean Si nanoripples, indicating the potential chemical modifications in the bacterial membrane and nucleic acids during the bactericidal effect.
\end{abstract}

Keywords: Si nanostructures; staphylococcus aureus bacterial biofilm; bactericidal effect; surface-enhanced IR microscopy; chemical enhancement

\section{Introduction}

Nanostructured surfaces of different materials exhibit unexpected and unprecedented bactericidal effects regarding pathogenic bacteria, which is usually related either to photochemical reaction of gaseous oxygen with composing nanocrystallites, yielding in reactive oxygen species and singlet oxygen [1-5], or to mechanical reaction of bacterial membranes to sharp surface nanoroughness [6-8]. Specifically, in the case of Si a broad variety of its nanomorph-nanospike [6], nanosheets [7] and nanoparticles (NPs) [9] were demonstrated to be bactericidal.

Moreover, surface-enhanced Raman scattering (SERS) and IR-absorption (reflection) (SEIRA/R) was performed on nanostructured Si surfaces, where linear- and non-linear optical enhancement could be achieved via plasmonic enhancement of local electric fields in heavily doped Si [10], magnetic dipolar resonance [11] or chemical charge-transfer processes. This increased the dipolar polarity between interacting surface and molecule functional groups [12], despite the fact that such 
a nanostructured material is sometimes considered as chemically inert [13]. Highly sensitive visible and near-IR SERS probes surface-adsorbed molecules only within the nanoscale interfacial region of the optical-range electrical near fields, making available for detection only the exterior elements of (sub) micro-scale viruses and bacteria [14-16]. In contrast, less-sensitive mid- and far-IR (typical wavelengths $\sim 3-25$ microns) SEIRA(R) probing involves the micro-scale interfacial region of the IR electrical near fields, being highly beneficial for characterization of specific internal elements in viruses and bacteria $[17,18]$. As a result, it is $\operatorname{SEIRA}(\mathrm{R})$ that potentially holds promise as a very important spectroscopic modality in characterizing key-enabling interactions of pathogenic bacteria and bactericidal nanostructured surfaces.

The main objective of this particular study was to use IR-microscopy of Staphylococcus aureus bacterial biofilms on different nanostructured silicon surfaces to reveal key interfacial chemical and physical interactions, and their underlying bactericidal effects. This study is facilitated by chemical enhancement of SEIRA signals via the same bactericidal and abiotic chemical bonding at these interfaces, opening the way for direct cellular and molecular scale analysis of their corresponding bactericidal performance.

\section{Experimental Results}

\subsection{IR Characterization of Bactericidal Si Nanoripples and Nanoparticle Coatings}

The nanopatterned Si spots indicated that weak homogeneous ablation of the wet Si wafers across the focused Gaussian beam was enhanced by strong nanoscale surface plasmon-mediated ablation, providing the polarization-dependent directionality of the generated 1D-nanoripples (Figure 1b-d). In both these fluids $\left(\mathrm{H}_{2} \mathrm{O}, \mathrm{CS}_{2}\right)$, the nanoripples appear as homogeneous regular arrays of ultra-thin Si 2D-nanosheets (thickness down to $30 \mathrm{~nm}$ ) with their "normal" orientation perpendicular to the laser polarization, similarly to common surface ripples $[19,20]$ but with the extraordinarily small period $\Lambda \approx 0.1 \mu \mathrm{m} \sim \lambda / 10$ and the extraordinarily tall $(<1 \mu \mathrm{m}$, aspect ratio $\sim 5)$ [7]. For comparison, the corresponding minimal ripple period in air approaches to $\Lambda$ (air) $\approx 0.9 \mu \mathrm{m}$ at the same normal orientation regarding the laser polarization (Figure 1d). Moreover, these nanoripples are tunable in their period, exhibiting considerable $(30 \%-40 \%)$ reduction of their periods versus the cumulative laser exposure $\mathrm{N}$-from $\Lambda\left(\mathrm{H}_{2} \mathrm{O}\right) \approx 0.18 \mu \mathrm{m}$ and $\Lambda\left(\mathrm{CS}_{2}\right) \approx 0.16 \mu \mathrm{m}$ at $\mathrm{N}=100$ until $\Lambda\left(\mathrm{H}_{2} \mathrm{O}\right) \approx 0.12 \mu \mathrm{m}$ and $\Lambda\left(\mathrm{CS}_{2}\right) \approx 0.1 \mu \mathrm{m}$ at $\mathrm{N}=2400$.

Fast Fourier-transform (FFT) IR micro-spectroscopy of the nanopatterned spots indicates considerable oxidation of the Si surfaces in Figure 1a-weak for the bare Si wafer, as shown by its absorbance spectrum with oxygen asymmetric stretching vibrational bands at 1075 and $1150 \mathrm{~cm}^{-1}$ [21]. In contrast, surprisingly the Si surface nanopatterns produced in carbon disulfide demonstrate much stronger oxygen asymmetric stretching vibrational bands at 1075 and $1150 \mathrm{~cm}^{-1}$. Apparently, this is considerably contributed to by $\mathrm{Si}-\mathrm{CH}_{2}$-Si wagging and $\mathrm{CH}_{3}$ symmetrical deformation in $\mathrm{Si}-\mathrm{CH}_{3}$ at 1020-1090 and 1250-1260 $\mathrm{cm}^{-1}$ [22], respectively. The additional strong bands at $1730(0.21 \mathrm{eV})$ and $2860-2960(0.37 \mathrm{eV}) \mathrm{cm}^{-1}$ correspond to, respectively, the dimer states of donor sulfur impurity in neutral $\left(\mathrm{S}_{2}{ }^{0}\right)$ and charged $\left(\mathrm{S}_{2}{ }^{+}\right)$states, lying at 0.188 and $0.37 \mathrm{eV}$ [23]. Meanwhile, elemental compositions of the patterns acquired by energy-dispersion X-ray spectroscopy (EDX) at $10 \mathrm{keV}$ (Table 1), strongly support our IR band assignment and analysis above, demonstrating for carbon disulfide ambient $\left(\mathrm{CS}_{2}\right)$ very significant relative contents of oxygen, carbon and sulfur-10 (O), $14(\mathrm{C})$ and $1(\mathrm{~S})$ at. \%, comparing to the water ambient $\left(\mathrm{H}_{2} \mathrm{O}\right)-2(\mathrm{O})$ and $6(\mathrm{C})$ at. \%, possibly, because of a film boiling isolation of the Si surface. Moreover, fs-laser patterning of Si in ambient air at the same laser and scanning parameters exhibits even stronger chemical modification-15 (O) and $17(\mathrm{C})$ at. \% (not shown), similarly to Si NPs produced by nanosecond laser ablation of the Si wafer in water (Figure 1e). All three types of patterns demonstrate a loss of structural order-LO/TO-line shift and broadening, presence of amorphous (a-Si) and high-pressure phases Si-III,XII [24] in Figure 2b, which is more pronounced for the wet patterning, specifically in $\mathrm{CS}_{2}$. 

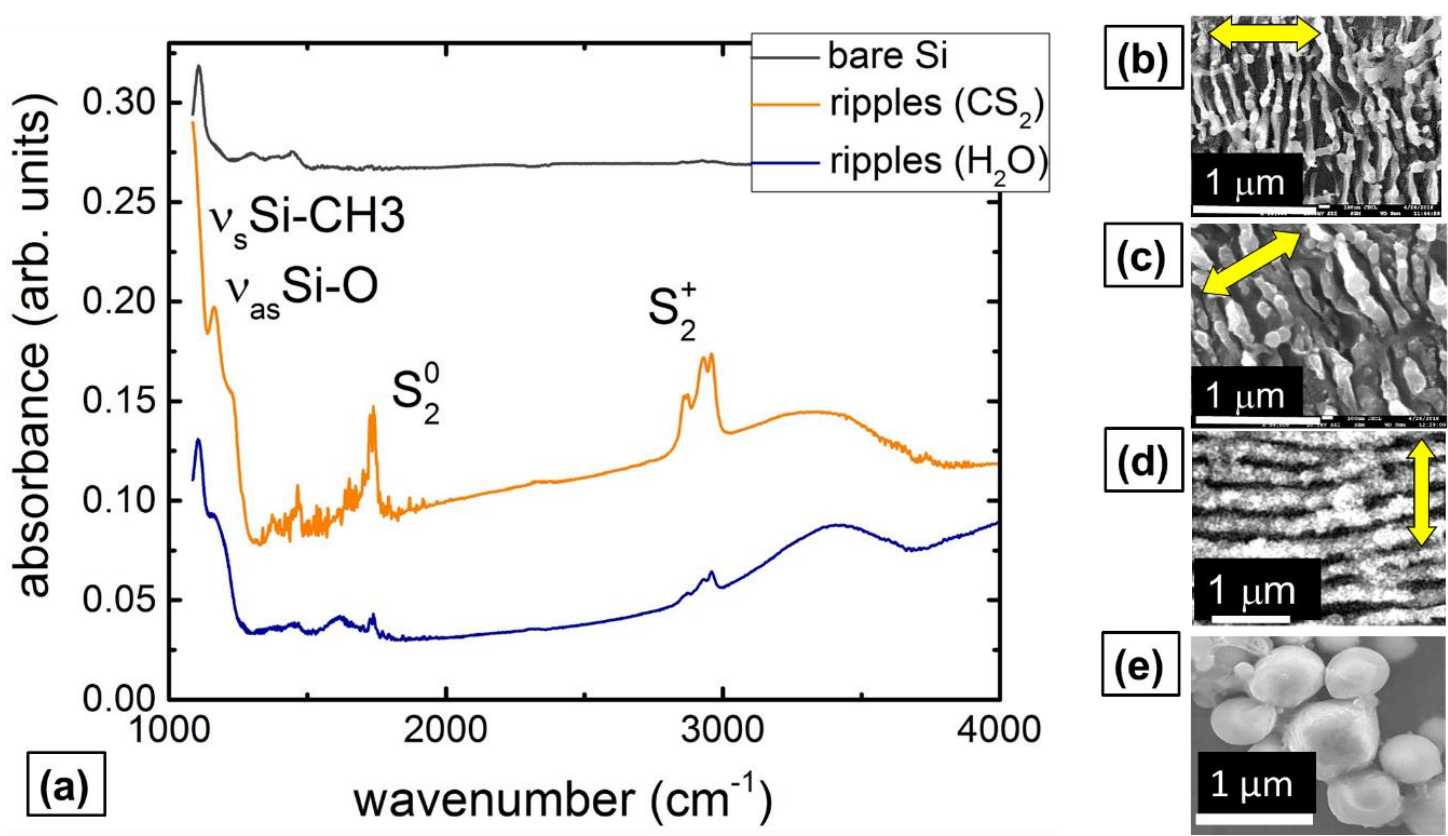

Figure 1. (a) IR absorbance spectrum of the bare Si wafer and IR absorbance spectra of nanostructured Si surfaces, normalized to the reference $\mathrm{Si}$ spectrum, with their principal band assignment. Insets: top-view SEM images of Si nanostructures laser patterned in $\mathrm{CS}_{2}(\mathbf{b}), \mathrm{H}_{2} \mathrm{O}(\mathbf{c})$ and air $(\mathbf{d})$, as a well as of Si NP coating (e).

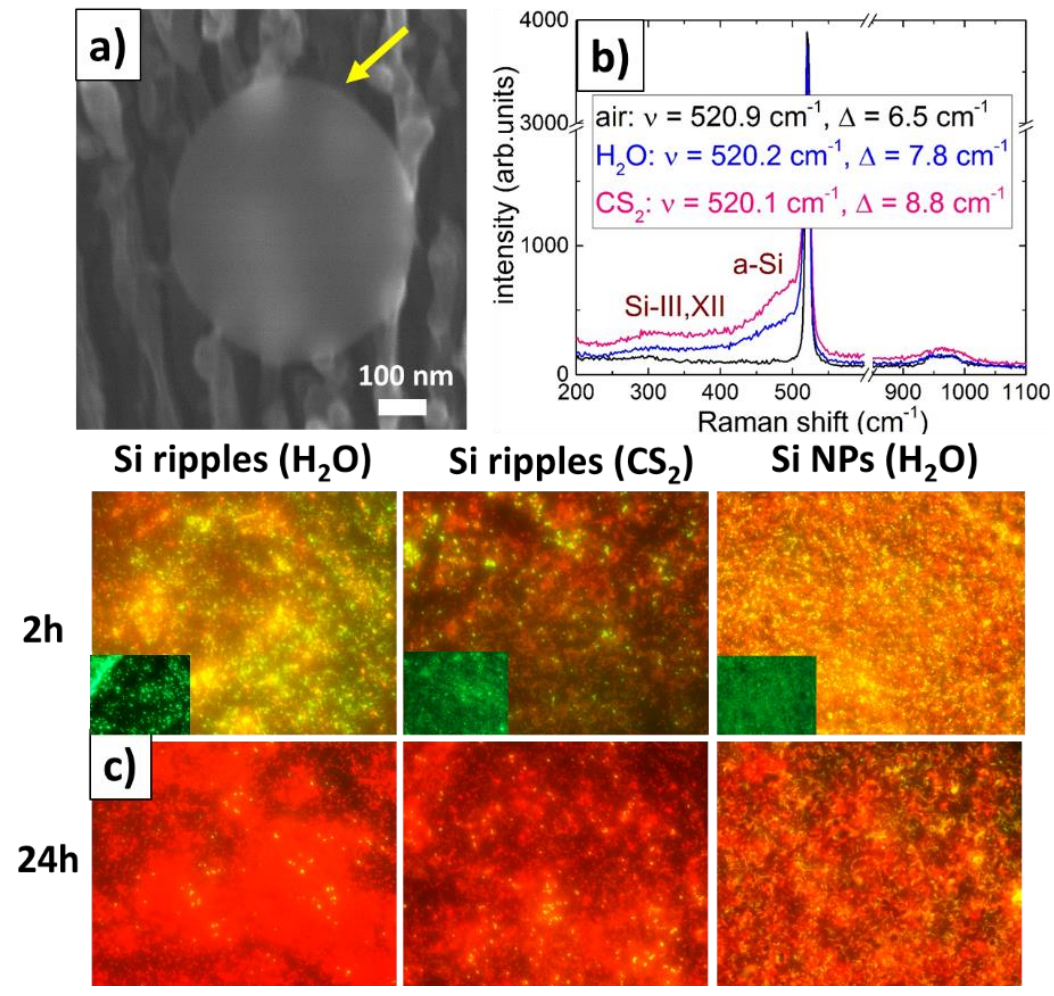

Figure 2. (a) Top-view SEM image of the nanosharp Si ripple pattern with the single inactivated Staphylococcus aureus bacterium (the bead marked by the yellow arrow). (b) Raman spectra of diverse Si surface ripples at the $488 \mathrm{~nm}$ excitation with their spectral and structural parameters (see the text above). (c) Images of stained live "green" (insets) and dead "red" Staphylococcus aureus bacteria on the Si nanopatterns and nanocoatings after $2 \mathrm{~h}$ and $24 \mathrm{~h}$ incubation. The frame sizes are $60 \times 90 \mu \mathrm{m}$. 
Table 1. Compositional chemical EDX analysis of the nanostructured Si surfaces.

\begin{tabular}{ccccc}
\hline $\begin{array}{c}\text { Structure/Chemical } \\
\text { Composition (at. \%) }\end{array}$ & Silicon Si & Oxygen O & Carbon C & Sulfur S \\
\hline Si ripples (air) & $67 \pm 1$ & $15 \pm 1$ & $17 \pm 1$ & 0 \\
\hline Si nanoripples $\left(\mathrm{CS}_{2}\right)$ & $75 \pm 1$ & $10 \pm 1$ & $14 \pm 1$ & $0.9 \pm 0.3$ \\
\hline Si nanoripples $\left(\mathrm{H}_{2} \mathrm{O}\right)$ & $92 \pm 1$ & $2 \pm 1$ & $6 \pm 1$ & 0 \\
\hline Si nanoparticles $\left(\mathrm{H}_{2} \mathrm{O}\right)$ & $84 \pm 1$ & $16 \pm 1$ & 0 & 0 \\
\hline
\end{tabular}

\subsection{IR Characterization of Staphylococcus Aureus Bacterial Biofilms on Bactericidal Si Nanoripples and} Nanoparticle Coatings

Recently, a fascinating "nanomechanical" bactericidal effect of Si surface nanoroughness was demonstrated relative to diverse pathogens $[6,8]$ being, potentially, accompanied or enhanced by chemical effect of singlet oxygen and other reactive oxygen species generated on illuminated $\mathrm{Si}$ surfaces [1,3]. In this study, despite the initial modest bactericidal response (red coloration due to the cell membrane damage upon $2 \mathrm{~h}$ incubation, Figure $2 \mathrm{c}$ ) for all these samples, the long-term ( $24 \mathrm{~h}$ ) effect appears to be more pronounced for the cleanest nanoripples produced in $\mathrm{H}_{2} \mathrm{O}$, while less pronounced for the disordered and chemically-modified nanoripples produced in liquid $\mathrm{CS}_{2}$, comparing to the even more minor effect for Si NPs. The observed bactericidal effect could occur owing to their good chemical binding to the clean nanostructured Si surface, unprecedented sharpness of the Si nanoripples, and, potentially, amorphous $\mathrm{Si}$ and sulfur contents, surface oxidation and carbonization, thus requiring the following research and analysis.

FFT-IR micro-spectroscopy of the Staphylococcus aureus bacterial biofilms on the nanostructured $\mathrm{Si}$ surfaces was performed with the control on the abiotic bare Si wafer surface (Figure 3). In this case, the relative absorbance of the bacterial films exhibits a number of typical bands [25]:

- in the window between 3000 and $2800 \mathrm{~cm}^{-1}\left(\mathrm{~W}_{1}\right.$, the 'fatty acid region $\left.\mathrm{I}^{\prime}\right)$, dominated by the $-\mathrm{CH}_{3}$, $>\mathrm{CH}$, and $=\mathrm{CH}$ stretching vibrations of the functional groups usually present in the fatty acid components of the various membrane amphiphiles;

- in the window between 1800 and $1500 \mathrm{~cm}^{-1}\left(\mathrm{~W}_{2}\right.$, the 'amide region'), dominated by the amide I and amide II bands of proteins and peptides;

- in the window between 1500 and $1200 \mathrm{~cm}^{-1}\left(\mathrm{~W}_{3}\right.$, the 'mixed region'), a spectral region containing information from proteins, fatty acids and phosphate-carrying compounds, including the window between 1500 and $1400 \mathrm{~cm}^{-1}\left(\mathrm{~W}_{31}\right.$, the 'fatty acid region II'), dominated by the $-\mathrm{CH}_{3}$ and $-\mathrm{CH}_{2}$ bending vibrations of the same functional groups as expressed in $\mathrm{W}_{1}$;

- in the window between 1200 and $900 \mathrm{~cm}^{-1}\left(\mathrm{~W}_{4}\right.$, the 'polysaccharide region'), dominated by the fingerprint-like absorption bands of the carbohydrates present within the cell wall.

On the bare Si substrate, the bacterial film demonstrates a rather weak own relative IR absorbance of all the characteristic bands, accounting for the corresponding IR transmittance of the underlying Si substrate.

In contrast, all these Si surface nanopatterns exhibit much stronger IR absorbance for all the characteristic absorption bands of Staphylococcus aureus bacteria (Figure 3), which is not the influence of their hydrophilic surface wetting (contact angles in the range of $\sim 40-70^{\circ}$ ). It appears $2-3$ fold more intense for Si-NP coating (Figure 4), 5-10 fold more intense for the Si nanopatterns produced in carbon disulfide, and 5-15 fold more intense for the less oxidized and carbonized Si nanopatterns produced in water. Since these characteristic absorption bands of Staphylococcus aureus bacteria are related above to the chemically active functional groups (fatty acids, amides, polycarbonates, proteins, peptides) of the Gram-positive cell membrane, their enhanced absorbance can be assigned to intense chemical interactions with the nanostructured surfaces. Such additional chemical bonding results in the interfacial chemical enhancement of the IR absorbance of Staphylococcus aureus bacteria in the 
SEIRA arrangement (Figure 4), more pronounced for the less passivated (oxidized, carbonized) Si surface nanopatterned in water.

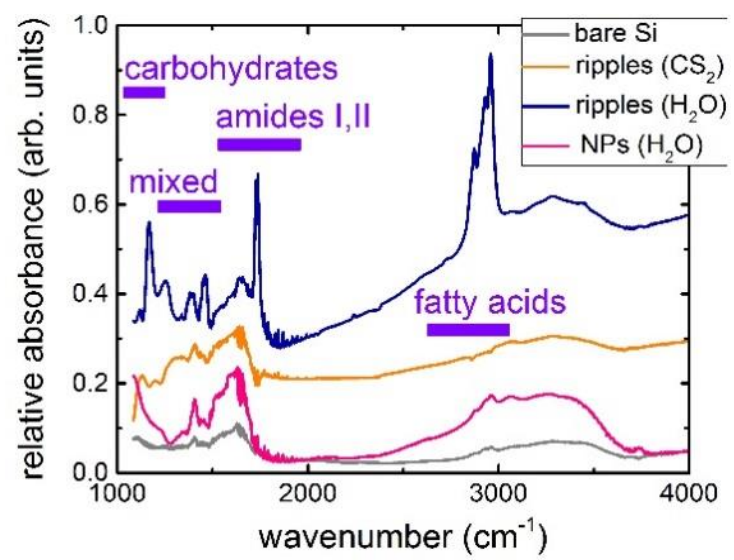

Figure 3. IR spectra of relative absorbance of the Staphylococcus aureus bacterial films on the nanostructured Si surfaces, normalized to their corresponding transmittances without bacterial films, with their principal band assignment after [22] (control-Staphylococcus aureus bacterial film on the bare smooth Si wafer). The upper spectrum is offset up by 0.15 for clarity.

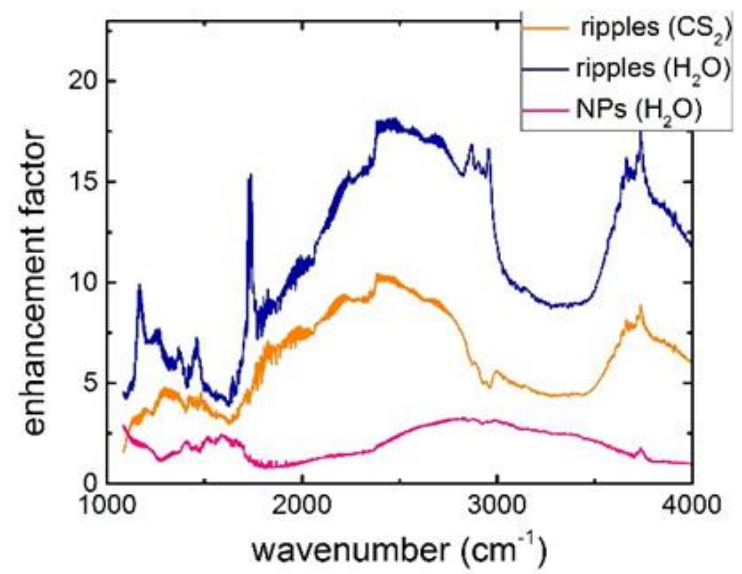

Figure 4. Enhancement factors for IR absorption in the Staphylococcus aureus bacterial films on the different nanostructured Si surfaces, normalized to the control absorbance spectrum of the same bacterial film on the smooth bare Si wafer.

Finally, a few strong and rather narrow, novel, additional absorption bands appeared in the IR absorbance spectra of Staphylococcus aureus bacteria at 1170 and $1740 \mathrm{~cm}^{-1}$ on the Si surfaces patterned in water (Figure 3), comparing even to previous UV-laser irradiation of such bacterial films [26]. These specific bands exhibit two orders of magnitude stronger absorbance (relative to the corresponding bands in the control experiments without background), emerging in the same characteristic absorption bands of Staphylococcus aureus bacterial membrane. However, the new emerging band at $1170 \mathrm{~cm}^{-1} \mathrm{can}$ be related to $\delta(\mathrm{COP}), \mathrm{C}-\mathrm{C}$ and $\mathrm{COH}$-vibrations in deoxyribonucleic acid (DNA) and ribonucleic acid (RNA) backbones [26], while the specific new band at $1740 \mathrm{~cm}^{-1}$ can be linked to $>\mathrm{C}=\mathrm{O}$ vibrations in lipid esters [26] or to peroxide oxidation of nucleic acids during oxidative stress, driven by reactive oxygen compounds [27].

Therefore, even though generally detailed principal component analysis of IR spectra of complex molecules or microorganisms is quite ambiguous, our results potentially indicate those chemical functional groups of the bacterial membrane, which predominantly interact with the rather clean nanostructured Si surface, apparently resulting in the bactericidal membrane damage ('external damage'), as shown by the red coloration of the bacteria in our live/dead tests due to the dye penetration 
through their membranes. Moreover, there are also some indications of bacterial RNA/DNA interactions with the nanostructured Si surfaces, potentially implying their internal chemical damage.

\section{Concluding Remarks}

In this study, the advanced surface-enhanced IR absorption (SEIRA) microscopic study of basic chemical and physical interactions between Staphylococcus aureus bacteria and state-of-the-art nanostructured bactericidal Si surfaces was performed, harnessing simultaneous chemical enhancement of the corresponding IR-absorption in the intact functional chemical groups. Cleaner, less passivated surface of Si nanoripples, laser-patterned in water, was observed to demonstrate much stronger SEIRA enhancement compared to the bare Si wafer, oxidized Si nanoparticles and oxidized/carbonized Si (nano) ripples, laser-patterned in air and water. Additional very strong bands emerge in the SEIRA spectra on the clean Si nanoripples, indicating the potential chemical modifications-both in the bacterial membrane and RNA/DNA backbones, during the bactericidal effect.

\section{Materials and Methods}

Si nanopatterns were fabricated via single-pass scanning of commercial Si (111) wafers in the form of their $2 \mathrm{~cm} \times 2 \mathrm{~cm}$ wide and $0.4 \mathrm{~mm}$ thick pieces by means of a laser nano/micromachining workstation. The nanopatterning was performed by $1030 \mathrm{~nm}, 300 \mathrm{fs}$ pulses of an ytterbium-doped fiber laser Satsuma, delivered at $6 \mu \mathrm{J}$ pulse energies $\left(\mathrm{TEM}_{00}\right.$ mode) and repetition rate $\mathrm{f}=160 \mathrm{kHz}$, focused onto the sample surface in a glass beaker into a spot with the $1 / \mathrm{e}$-radius $\sigma_{1 / \mathrm{e}} \approx 15 \mu \mathrm{m}$ (the peak fluence $\left.\approx 1 \mathrm{~J} / \mathrm{cm}^{2}\right)$ through $5 \mathrm{~mm}$ thick carbon disulfide $\left(\mathrm{CS}_{2}\right)$ or double-distilled water. Surface scanning was provided by a galvanoscanner ATEKO ${ }^{\mathrm{TM}}$ with 100 lines/mm surface filling and $13 \mu \mathrm{m}$ inter-spot distance in the lines at scan velocity $\mathrm{V}=12 \mathrm{~mm} / \mathrm{s}$ (the corresponding surface exposure $\mathrm{N}=$ $2 \sigma_{1 / \mathrm{e}} \mathrm{f} / \mathrm{V}=400$ shots per spot). Surface topography and chemical composition of the nanopatterned samples were characterized by means of a scanning electron microscope (SEM) JEOL 7001F, equipped by an energy-dispersion x-ray spectroscopy (EDX) module INCA (Oxford Instruments, UK) for chemical micro-analysis at the $10 \mathrm{keV}$ kinetic energies of electrons. Raman micro-spectroscopy of the nanopatterned samples was performed at the $488 \mathrm{~nm}$ wavelength (U-1000, Jobin Yvon, France).

The anticipated antibacterial effect of the fabricated Si nanopatterns (nanoripples) was tested on the next day on Gram-negative clinical isolate Staphylococcus aureus bacteria as biofilms. The method of obtaining bacterial biofilms with its subsequent coloration using "Live/Dead Biofilm Viability Kit" was described elsewhere [7]. Specifically, $18 \mathrm{~h}$ culture of the bacteria grown in a nutrient medium (LB), was diluted with fresh LB in the proportion 1:100. A Petri dish with the broth culture was placed for investigation. For biofilm formation, the samples of the Si wafers fs-laser nanopatterned in air, water $\left(\mathrm{H}_{2} \mathrm{O}\right)$ and carbon disulfide $\left(\mathrm{CS}_{2}\right)$ ambients, were incubated for $24 \mathrm{~h}$ at $37{ }^{\circ} \mathrm{C}$. A "Live/Dead Biofilm Viability Kit" coloration set was used to differentiate between viable and non-viable bacteria in the biofilms. SYTO ${ }^{\circledR} 9$ green fluorescent dye (component A) and propidium iodide (component B) red fluorescent dye formed the complete staining set. The staining method is based on the penetration of the two dyes into the bacterial cells. SYTO ${ }^{\circledR} 9$ (3.34 mM in DMSO) dye binds to DNA and stains both live and dead bacteria with damaged and intact cell membranes, while propidium iodide (20 mM in DMSO) dye colors dead bacteria with damaged cell membranes. To visualize the bacterial biofilms, the fluorescent dyes: $3 \mu \mathrm{L}$ SYTO ${ }^{\circledR} 9$ and $3 \mu \mathrm{L}$ propidium iodide were diluted in $1 \mathrm{~mL}$ of distilled water. Then, the nutrient medium was removed from the Petri dish and biofilms on the samples were submerged in a solution from the "Live/Dead Biofilm Viability Kit" for 15 min in darkness. After incubation, the samples were immediately washed three times with water and analyzed, using the fluorescence microscope Nikon H600L with a 40x fluorescence objective lens (instrumental magnification-600x). IR-micro-spectroscopy of the nanopatterned samples with and without bacterial films was performed in a transmission mode in the range of $400-7000 \mathrm{~cm}^{-1}$ (Thermo Nicolet Nexus 470 FT-IR spectrometer, USA). 
For IR-spectroscopic characterization, clinical isolates from the collection of the genetic engineering laboratory of pathogenic microorganisms were used: Staphylococcus aureus 15 and Pseudomonas aeruginosa 32. Bacterial cultures were grown in Luria-Bertani (LB) liquid medium using standard dry and liquid culture media manufactured by Difco (New York, NY, USA). Then, $1 \mathrm{~mL}$ of overnight broth culture of bacteria was placed in a sterile tube and centrifuged for $5 \mathrm{~min}$ at $3000 \times \mathrm{g}$. Then the cultures were washed three times with sterile $\mathrm{NaCl}$, each time separating the cells by centrifugation. Finally, prior to spectroscopy, the resulting bacterial suspensions in $\mathrm{NaCl}$ solution, taken in the quantity of $100 \mu \mathrm{L}$, were transferred to various substrates and dried.

Author Contributions: Writing and editing, S.I.K. and T.E.I.; investigation and data analysis, A.A.N. and E.R.T.; IR-microscopy measurements and principal spectral analysis, A.N.K. and A.Y.P.; SEM visualization and EDX characterization, I.N.S. and A.A.R.; conceptualization and project management, A.A.I. and Y.M.R.

Funding: This work was supported by the Russian Science Foundation (grant \# 18-15-00220) in the part of the bactericidal effect and Ministry of science and higher education (Grant 074-U01 for ITMO University, professorship of S.I. Kudryashov) in the part of the IR micro-spectroscopic analysis.

Conflicts of Interest: The authors declare no conflicts of interest.

\section{References}

1. Fu, P.P.; Xia, Q.; Hwang, H.M.; Ray, P.C.; Yu, H. Mechanisms of nanotoxicity: Generation of reactive oxygen species. J. Food Drug Anal. 2014, 22, 64-75. [CrossRef] [PubMed]

2. Xiao, L.; Gu, L.; Howell, S.B.; Sailor, M.J. Porous Silicon Nanoparticle Photosensitizers for Singlet Oxygen and their Phototoxicity against Cancer Cells. ACS Nano 2011, 5, 3651-3659. [CrossRef] [PubMed]

3. Timoshenko, V.Y.; Kudryavtsev, A.A.; Osminkina, L.A.; Vorontsov, A.S.; Ryabchikov, Y.V.; Belogorokhov, I.A.; Kovalev, D.; Kashkarov, P.K. Silicon nanocrystals as photosensitizers of active oxygen for biomedical applications. Jetp Lett. 2006, 83, 423-426. [CrossRef]

4. Chernousova, S.; Epple, M. Silver as antibacterial agent: Ion, nanoparticle, and metal. Angew. Chem. Int. Ed. 2013, 52, 1636-1653. [CrossRef] [PubMed]

5. Nastulyavichus, A.; Kudryashov, S.; Smirnov, N.; Saraeva, I.; Rudenko, A.; Tolordava, E.; Ionin, A.; Romanova, Y.; Zayarny, D. Antibacterial coatings of Se and Si nanoparticles. Appl. Surf. Sci. 2019, 469, 220-225. [CrossRef]

6. Ivanova, E.P.; Hasan, J.; Webb, H.K.; Gervinskas, G.; Juodkazis, S.; Truong, V.K.; Wu, A.H.F.; Lamb, R.N.; Baulin, V.A.; Watson, G.S.; et al. Bactericidal activity of black silicon. Nat. Commun. 2013, 4, 2838. [CrossRef]

7. Kudryashov, S.I.; Nguyen, L.V.; Kirilenko, D.A.; Brunkov, P.N.; Rudenko, A.A.; Busleev, N.I.; Saraeva, I.N.; Nastulyavichus, A.A.; Ionin, A.A.; Tolordava, E.R.; et al. Large-scale Laser Fabrication of Anti-Fouling Si Surface Nanosheet Arrays via Nanoplasmonic Ablative Self-organization in Liquid CS2 Tracked by Sulfur Dopant. ACS Appl. Nano Mater. 2018, 1, 2461-2468. [CrossRef]

8. Linklater, D.P.; Juodkazis, S.; Ivanova, E.P. Nanofabrication of Mechano-Bactericidal Surfaces. Nanoscale 2017, 9, 16564-16585. [CrossRef]

9. Smirnov, N.A.; Kudryashov, S.I.; Nastulyavichus, A.A.; Rudenko, A.A.; Saraeva, I.N.; Tolordava, E.R.; Gonchukov, S.A.; Romanova, Y.M.; Ionin, A.A.; Zayarny, D.A. Antibacterial properties of silicon nanoparticles. Laser Phys. Lett. 2018, 15, 105602. [CrossRef]

10. Milla, M.J.; Barho, F.; González-Posada, F.; Cerutti, L.; Charlot, B.; Bomers, M.; Neubrech, F.; Tournie, E.; Taliercio, T. Surface-enhanced infrared absorption with Si-doped InAsSb/GaSb nano-antennas. Opt. Express 2017, 25, 26651-26661. [CrossRef]

11. Caldarola, M.; Albella, P.; Cortés, E.; Rahmani, M.; Roschuk, T.; Grinblat, G.; Oulton, R.F.; Bragas, A.V.; Maier, S.A. Non-plasmonic nanoantennas for surface enhanced spectroscopies with ultra-low heat conversion. Nat. Commun. 2015, 6, 7915. [CrossRef] [PubMed]

12. Xia, L.; Chen, M.; Zhao, X.; Zhang, Z.; Xia, J.; Xu, H.; Sun, M. Visualized method of chemical enhancement mechanism on SERS and TERS. J. Raman Spectrosc. 2014, 45, 533-540. [CrossRef]

13. Mitsai, E.; Kuchmizhak, A.; Pustovalov, E.; Sergeev, A.; Mironenko, A.; Bratskaya, S.; Linklater, D.P.; Balčytis, A.; Ivanova, E.; Juodkazis, S. Chemically non-perturbing SERS detection of a catalytic reaction with black silicon. Nanoscale 2018, 10, 9780-9787. [CrossRef] [PubMed] 
14. Mosier-Boss, P.A. Review on SERS of Bacteria. Biosensors 2017, 7, 51. [CrossRef]

15. Liu, Y.; Zhou, H.; Hu, Z.; Yu, G.; Yang, D.; Zhao, J. Label and label-free based surface-enhanced Raman scattering for pathogen bacteria detection: A review. Biosens. Bioelectron. 2017, 94, 131-140. [CrossRef]

16. Zheng, X.S.; Jahn, I.J.; Weber, K.; Cialla-May, D.; Popp, J. Label-free SERS in biological and biomedical applications: Recent progress, current challenges and opportunities. Spectrochim. Acta Part. A Mol. Biomol. Spectrosc. 2018, 197, 56-77. [CrossRef]

17. Lamprell, H.; Mazerolles, G.; Kodjo, A.; Chamba, J.F.; Noel, Y.; Beuvier, E. Discrimination of Staphylococcus aureus strains from different species of Staphylococcus using Fourier transform infrared (FTIR) spectroscopy. Int. J. Food Microbiol. 2006, 108, 125-129. [CrossRef]

18. Danilov, P.A.; Gonchukov, S.A.; Ionin, A.A.; Khmelnitskii, R.A.; Kudryashov, S.I.; Nguyen, T.T.H.; Rudenko, A.A.; Saraeva, I.N.; Zayarny, D.A. Background-free, highly-sensitive surface-enhanced IR absorption of rhodamine 6G molecules deposited onto array of microholes in thin silver film. Laser Phys. Lett. 2016, 13, 055602. [CrossRef]

19. Bonse, J.; Krüger, J.; Höhm, S.; Rosenfeld, A. Femtosecond laser-induced periodic surface structures. J. Laser Appl. 2012, 24, 042006. [CrossRef]

20. Tsibidis, G.D.; Skoulas, E.; Stratakis, E. Ripple formation on nickel irradiated with radially polarized femtosecond beams. Opt. Lett. 2015, 40, 5172-5175. [CrossRef]

21. Pai, P.G.; Chao, S.S.; Takagi, Y.; Lucovsky, G. Infrared spectroscopic study of SiO x films produced by plasma enhanced chemical vapor deposition. J. Vac. Sci. Technol. A Vac. Surf. Film. 1986, 4, 689-694. [CrossRef]

22. Kim, M.T.; Lee, J. Characterization of amorphous SiC: H films deposited from hexamethyldisilazane. Thin Solid Film. 1997, 303, 173-179. [CrossRef]

23. Grimmeiss, H.G.; Janzen, E.; Skarstam, B. Deep sulfur-related centers in silicon. J. Appl. Phys. 1980, 51, 4212-4217. [CrossRef]

24. Ionin, A.A.; Kudryashov, S.I.; Levchenko, A.O.; Nguyen, L.V.; Saraeva, I.N.; Rudenko, A.A.; Ageev, A.A.; Potorochin, D.V.; Veiko, V.P.; Borisov, E.V.; et al. Correlated topographic and structural modification on Si surface during multi-shot femtosecond laser exposures: Si nanopolymorphs as potential local structural nanomarkers. Appl. Surf. Sci. 2017, 416, 988-995. [CrossRef]

25. Helm, D.; Labischinski, H.; Schallehn, G.; Naumann, D. Classification and identification of bacteria by Fourier-transform infrared spectroscopy. Microbiology 1991, 137, 69-79. [CrossRef] [PubMed]

26. Krishnamurthy, K.; Tewari, J.C.; Irudayaraj, J.; Demirci, A. Microscopic and spectroscopic evaluation of inactivation of Staphylococcus aureus by pulsed UV light and infrared heating. Food Bioprocess. Technol. 2010, 3, 93. [CrossRef]

27. Faghihzadeh, F.; Anaya, N.M.; Schifman, L.A.; Oyanedel-Craver, V. Fourier transform infrared spectroscopy to assess molecular-level changes in microorganisms exposed to nanoparticles. Nanotechnol. Environ. Eng. 2016, 1, 1. [CrossRef]

Sample Availability: Samples of the compounds are available from the authors.

(C) 2019 by the authors. Licensee MDPI, Basel, Switzerland. This article is an open access article distributed under the terms and conditions of the Creative Commons Attribution (CC BY) license (http://creativecommons.org/licenses/by/4.0/). 